\title{
Metaflammation, NLRP3 Inflammasome, Obesity and Metabolic Disease
}

\author{
Anna Meiliana ${ }^{1,2 *}$ and Andi Wijaya ${ }^{1,2 *}$ \\ ${ }^{1}$ Post Graduate Program in Clinical Biochemistry, Hasanuddin University, Jl. Perintis Kemerdekaan Km.10. Makassar, Indonesia \\ ${ }^{2}$ Prodia Clinical Laboratory, Jl. Cisangkuy No.2, Bandung, Indonesia \\ *Correspondence: anna_m@prodia.co.id
}

\section{Abstract}

$\mathrm{B}$ ACKGROUND: Increasing prevalence of obesity gives rise to many problems associated with multiple morbidities, such as diabetes, hypertension, heart disease, sleep apnea, and cancer. The mechanism of obesity is very complex, thus its link to various disease is poorly understood. This review highlights important concepts in our understanding of the pathogenesis of obesity and related complications.

CONTENT: Many studies have tried to explore the exciting and puzzling links between metabolic homeostasis and inflammatory responses. A form of subclinical, lowgrade systemic inflammation is known to be associated with both obesity and chronic disease. This, later called as "metaflammation", refers to metabolically triggered inflammation. The nutrient-sensing pathways and the immune response coordination are facilitated by these molecular sites in order to maintain homeostasis under diverse metabolic and immune conditions. Recent studies have found that the NLRP3 inflammasome during metabolic stress forms a tie linking TXNIP, oxidative stress, and IL- $1 \beta$ production. This provides new opportunities for research and therapy for the disease often described as the next global pandemic: type 2 diabetes mellitus (T2DM).

SUMMARY: The crucial role of metaflammation in many complications of obesity shown by the unexpected overlap between inflammatory and metabolic sensors and their downstream tissue responses. Then great interest arose to explore the pathways that integrate nutrient and pathogen sensing, give more understanding in the mechanisms of insulin resistance type 2 diabetes, and other chronic metabolic pathologies. A family of intracellular sensors called NLR family is a critical component of the innate immune system. They can form multiprotein complexes, called inflammasome which is capable of responsing to a wide range of stimuli including both microbial and self molecules by activating the cysteine protease caspase-1, leading to processing and secretion of the proinflammatory cytokines IL-1 $\beta$ and IL-18, which play crucial roles in host defense. Inflammasome dysregulation has been linked to some autoinflammatory and metabolic diseases. These provide opportunities to continue to improve our understanding of the nature of metaflammation in the hope of modifying it to prevent and treat diseases.

KEYWORDS: Inflammation, Metaflammation, Inflammasome, Metabolic Disease, Obesity

Indones Biomed J 2011; 3 (3): 168-184

\section{Introduction}

The WHO estimated that in 2008, 1.5 billion adults aged 20 years and older were overweight and - approximately $10 \%$ of adults - over 200 million men and 300 million women were obese. In 2010, about 43 million children 
under five years of age were overweight (5). Obesity is no longer a problem for high-income developed countries alone. In fact, since 1908 the largest increases in obesity particularly in urban settings in Oceania, Asia, Latin America, and North Africa occurred in low and middleincome countries, $(1,2)$. This was due to a shift in diet toward energy-dense rich in fat and sugar foods but low in vitamins and other micronutrients $(1,2)$.

Epidemiologic data indicate that chronic intake of fatty diets and fructose and frequent consumption of fast food increase the risk of obesity (3-8). Global changes in diet and physical inactivity have been fueled by changes in agricultural practices, food processing, marketing and distribution, transportation, and other aspects of urban planning. Collectively, this "obesogenic environment" predisposes to diabetes, cardiovascular disease, osteoarthritis, sleep apnea, cancer, and other ailments (9-12).

Thus, there is an urgent need for understanding of the regulation of energy homeostasis and how obesity causes diabetes and other complications. Recent works have highlighted the impact of obesity to activate inflammatory gene networks and suggest a causal function of inflammation in the pathogenesis of the metabolic syndrome. Since 2005, when Dr Gokhan Hotamisligil chaired the fourth Stock Conference in Istanbul, Turkey, entitled 'Obesity and Inflammation', there has been an explosion of studies investigating the relationship between obesity, inflammation and substrate metabolism.

In April 2009, The International Association for the Study of Obesity (IASO) convened a 3-d conference in Palm Cove, Cairns, Australia to address the role of inflammation in the etiology of obesity and the metabolic syndrome (13). It is clear that chronic lowgrade inflammation is a common molecular underpinning involved in the pathogenesis of insulin resistance, the metabolic syndrome, type 2 diabetes, cardiovascular disease and certain forms of cancer (13).

Inflammation is a coordinated response to harmful stimuli, with the goal of returning the system back to a normal baseline. The inflammatory response triggered by obesity involves many components of the classical inflammatory response to pathogens and includes systemic increases in circulating inflammatory cytokines and acute phase proteins (e.g., C-reactive protein), recruitment of leukocytes to inflamed tissues, activation of tissue leukocytes, and generation of reparative tissue responses (14). However, the nature of obesity-induced metaflammation is unique as compared with other inflammatory paradigms (e.g., infection, autoimmune disease) in several key aspects. The chronic nature of obesity produces a tonic low-grade activation of the innate immune system that affects steady-state measures of metabolic homeostasis over time (15).

A close relationship exists between nutrient excess and derangements in the cellular and molecular mediators of immunity and inflammation. This has given birth to the concept of "metaflammation" (16) to describe the chronic low-grade inflammatory response to obesity. Inflammasomes are molecular platforms activated upon cellular infection or stress that trigger the maturation of proinflammatory cytokines such as IL- $1 \beta$ to engage innate immune defenses. Strong associations between dysregulated inflammasome activity and human heritable and acquired inflammatory diseases highlight the importance of this pathway in tailoring immune responses. The nucleotide-binding domain, leucine-richcontaining family, pyrine domain-containing-3 (NLRP3) inflammasome functions as a sensor to detect danger signals and induces downstream inflammatory signaling that contributes to obesity-associated conditions such as insulin resistance $(17,18)$.

These findings suggest that the NLRP3 inflammasome is a missing piece in the puzzle of the complex mechanisms involved in the onset of the metabolic syndrome and can be a potential target for treatment of insulin resistance (19).

\section{Obesity and Adipose Tissue Remodelling}

Obesity constitutes a collateral damage in the battle for modernity. It is the burden many of us bear as a result of our inability, or unwillingness, to adjust to the energy surpluses emanating from economic advancement. A causal association between obesity and a wide range of diseases has been well documented. However, recent findings suggest a more complicated etiological role than just a simple weight-disease association (20). Dependent largely on the site of fat storage, obesity can be relatively benign, with little negative impact on physical health (21) (although admittedly with an often significant psychological effect), or metabolic, with significant links to metabolic and other disorders (22). On the other hand, a clear link has been established between certain lifestyle factors (aspects of nutrition, inactivity, inadequate sleep, stress, depression, excessive alcohol intake, smoking), which sometimes, but not always, lead to obesity, and a type of low-grade systemic inflammation, which is associated with a range of chronic diseases $(16,23)$. 
A certain amount of body fat in mammals is essential for survival (24). It serves as an energy reserve, a storage mechanism for vital nutrients and a form of insulation. Recent findings have shown that it also acts as an endocrine organ (25) as well as having a close link to the immune system (16).

Recently, it has been shown that excessive visceral adipose tissue (VAT) is even more predictive of metabolic disorders originally associated with subcutaneous adipose tissue (SAT) (26-28), and that there may even be an inverse association with metabolic problems and gluteal fat stores (29). Variability in VAT has been proposed as the underlying cause for the significant proportion of obese individuals (estimated to be around $20 \%$ ) without health risks, and a similar proportion of lean individuals with such risks (30).

Excessive VAT, or an increased VAT/SAT ratio is strongly associated with macrophage infiltration and is an inflammatory state (31), which has possible links with oxidative stress. Oxidative stress (32) and inflammation (33), in turn, have been linked to insulin resistance, and ultimately, to cardio-metabolic disorders (34). Obesity is thought to be an instigator of this process (35).
There are a number of lifestyle-related inducers that have been associated with oxidative stress and/or inflammatory processes in the body, as well as with insulin resistance and potential cardio-metabolic disease. Within these categories, there are also inducers associated with pro-and anti-inflammatory or neutral processes.

Figure 1 shows environmental inducers with evidence of a causal link with metaflammation and consequent chronic diseases. Some of these have dependent links with obesity, as well as independent effects, but some also affect metaflammation without any connection to obesity (36). Increasing evidence suggests that while obesity is a health risk, it may not necessarily be the direct cause, but may instead be a marker of many modern chronic diseases. The distal cause appears to lie in a maladaptive environment facilitating lifestyle behaviors and stimuli to which humans have not had time to adjust, leading us to 'treat our own cells like invading microbes' (37).

Adipose tissue (AT) can respond rapidly and dynamically to alterations in nutrient deprivation and excess through adipocyte hypertrophy and hyperplasia, thereby fulfilling its major role in whole body energy homeostasis. AT remodeling is an ongoing process

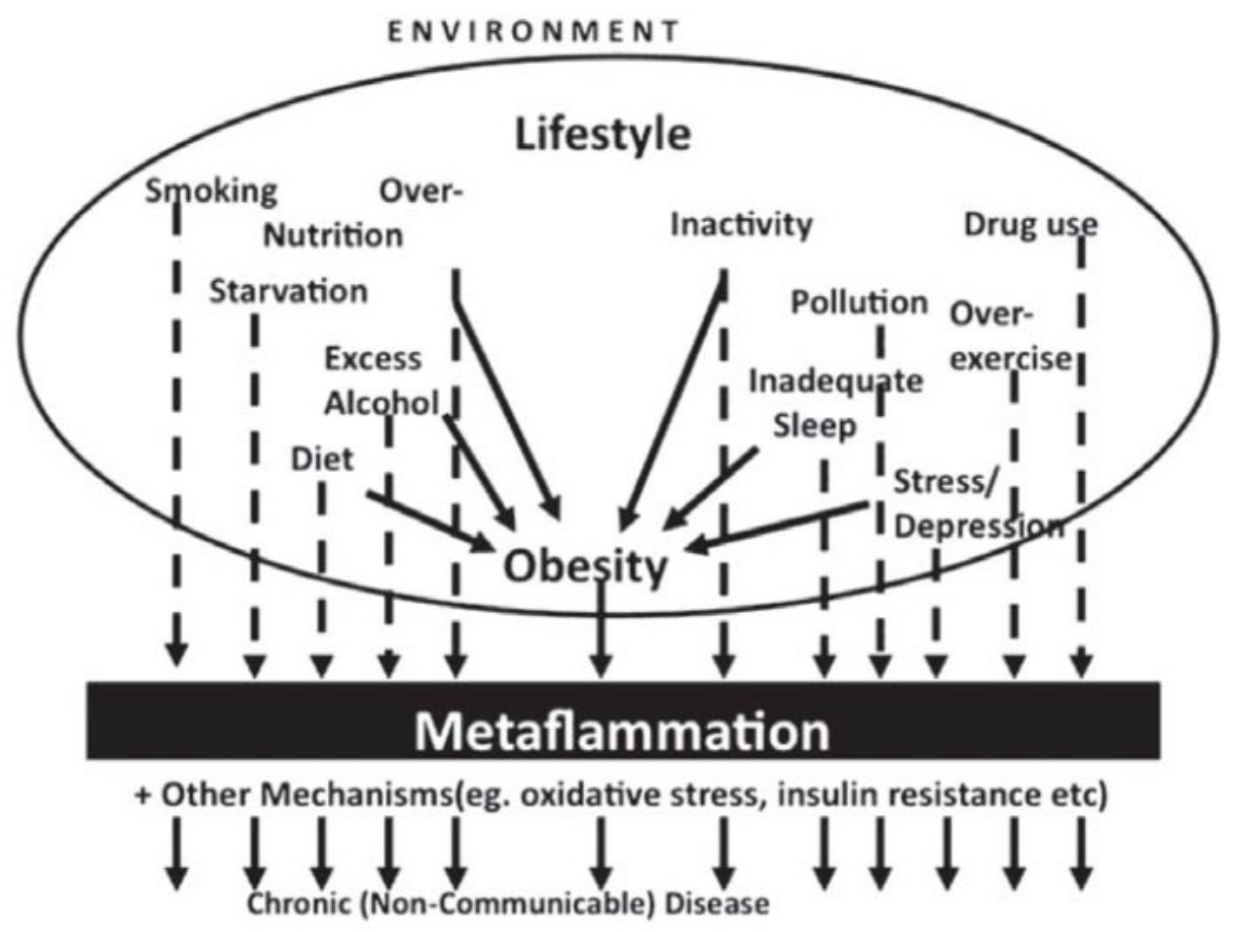

Figure 1. Environmental and lifestyle 'inducers' of metaflammation showing both independent and dependent effects through obesity (Adapted with permission from Egger J et al. , John Wiley \& Sons, Inc 2009). 
that is pathologically accelerated in the obese state and thus, features such as reduced angiogenic remodeling, ECM overproduction, a heightened state of immune cell infiltration and subsequent proinflammatory responses prevail in many obese fat-pads (35).

Adipocyte hyperplasia and hypertrophy can both contribute to AT expansion. This expansion can lead to a myriad of effects including hypoxia, adipocyte cell death, enhanced chemokine secretion, and dysregulation in fatty acid fluxes (38). Such adipocyte-related consequences pose major logistical challenges and require macrophages to create a permissive environment for the remodeling process. Adipocytes are therefore at the very core of initiation of macrophage recruitment.

The "initiation" of macrophage infiltration into adipose involved four different mechanisms (39):

\section{Adipocyte death}

As "professional" phagocytes, macrophages are extremely proficient in the removal of numerous molecules, ranging from small lipids to colonies of pathogens to dead cells (40). Cinti and colleagues hypothesized that necrosis of adipocytes, driven by hypertrophy and accelerated by obesity, is a prominent phagocytic stimulus that regulates ATM $\Phi$ infiltration (41). Indeed, macrophages have been shown to aggregate, forming crown-like structures (CLSs) surrounding necrotic adipocytes in advanced obesity (41-44). In this state, they fuse to phagocytose the residual lipid droplet, forming large lipid-laden multinucleated syncytia in the process, a commonly accepted hallmark of chronic inflammation $(41,45)$.

\section{Chemotactic regulation}

Chemokines are small proinflammatory molecules that promote macrophage mobilization from bone marrow into tissues. There is considerable evidence for the pathophysiological role of macrophage-and/ or hypertrophic adipocyte-derived chemotactic MCP-1/CCR2 pathways in the regulation of monocyte accumulation in obese AT $(46,47)$. In particular, increased expression levels of MCP-1, CXCL14, MIP-1 $\alpha$, MCP-2, MCP-3, and RANTES can be observed in AT of mice with genetic or dietinduced obesity (DIO) $(46,48,49)$.

\section{Hypoxia}

Adipocyte hypertrophy creates areas of local AT microhypoxia at the earliest stages of expansion (50). The effects of the local AT hypoxia have been investigated both in isolated murine adipocytes and in animal models (51-55). This suggests that many adipokines are related to inflammation such as macrophage migration inhibitory factor (MIF), the matrix metalloproteinases (MMP)-2 and MMP9, IL-6, Angplt4, PAI-1, VEGF, and leptin are all upregulated by hypoxia (52-55). A master regulator of hypoxia and oxygen homeostasis is HIF-1. Several important hypoxia-associated genes, such as leptin and VEGF, are directly regulated by HIF-1 (55).

\section{Fatty acid flux}

FFAs, stored in the form of triglycerides in AT, are released from hypertrophic adipocytes through lipolysis during fasting. Some of these FFAs are shunted to the liver and stored in lipid droplets, while some of them are oxidized in other organs. However, FFAs can also serve as ligands for the TLR4 complex (56), thereby activating the classical inflammatory response in the context of increased local extracellular lipid concentrations, which ultimately drives ATM $\Phi$ accumulation $(57,58)$.

While these four mechanisms of macrophage recruitment and infiltration into AT may act independently, the metabolic and inflammatory pathways are tightly interconnected.

In 2007, Saltiel and colleagues proposed a model of "phenotypic switching" that captured the very essence by which enhanced ATM $\Phi$ infiltration exacerbates the milieu of obesity-related inflammation (59). Their model emphasized that obesity is accompanied by a transformation in the polarized states of macrophages, from an antiinflammatory "alternatively activated" M2 form that primarily accumulates during negative energy balance $(60)$ to a more proinflammatory "classically activated" M1 form (59). The M1 population demonstrates a positive correlation with insulin resistance and dominates in states of overnutrition by targeting FFA-mediated increases in proinflammatory responses $(45,61)$. Taken together, these studies suggest that a delicate balance of polarized populations of macrophages is necessary to maintain adequate adipocyte function (39).

Noteworthy, it is an active crosstalk between adipocytes, preadipocytes and macrophages which results in a perpetuation of pro-inflammatory response. In line with this, pro-inflammatory cytokines and macrophages can be considered relevant factors involved in obesityrelated disorders such as insulin insensitivity, type 2 diabetes and atherosclerosis (62). 
Interestingly, saturated fatty acids, which are released via macrophage-induced adipocyte lipolysis, may act as naturally occurring ligands for the Toll-like receptor (TLR) 4 complex, which is essential for the recognition of LPS, to induce nuclear factor (NF)-kB activation in macrophages (63). Given their multifunctional roles in a variety of biological contexts, macrophages should play a central role in adipose tissue remodeling, thereby regulating adipocytokine production $(16,63)$.

\section{Inflammation - Metaflammation}

Classical inflammation represents an acute immune reaction to infection or injury. Metaflammation (16) differs from this in that: (a) it does not involve the classical symptoms of inflammation (tumor, rubor, dolor and calor); (b) it causes only a small rise in immune system markers (i.e. 4-6-fold v. several 100-fold); (c) it results in chronic, rather than acute, allostasis; (d) it has its effects systemically; (e) its antigens are less apparent as foreign agents or microbial organisms (and hence may be better referred to as 'inducers'(6)); (f) it appears to perpetuate, rather than resolve, a disease $(16,34,35,64,65)$.
Obesity is a cause of oxidative stress and insulin resistance (34) and hence has been proposed as the primary causative factor in chronic and metabolic diseases such as type 2 diabetes (67). However, depending largely on the site of fat storage, obesity can be relatively benign, with little negative impact on health (67), or metabolic, with apparent links to a range of metabolic and other disorders (22).

There is a known link between obesity and metaflammation $(34,35)$, but the causal relationship is not clear. Metaflammation is also associated with lifestyle and environmental factors that in some instances, but not always, cause obesity (36). Inducers with evidence of a pro-inflammatory (metaflammatory) response, as well as obesity and weight gain, this includes excessive alcohol (68), acute excess energy intake (69), a Westernstyle diet (70) and a range of nutritive factors including saturated (71) and trans-fats (72), and excessive fructose(73) and glucose-rich foods (74). Non-nutritive factors include inadequate sleep (75), smoking (76), stress and depression (77). Nutrient overload from acute excessive energy intake, for example, even in the absence of weight gain (78), can abnormally tax the intracellular metabolism, cause acute oxidative stress, possibly disrupt normal protein folding in the endoplasmic reticulum (65) and lead to the accumulation of intracellular metabolites,

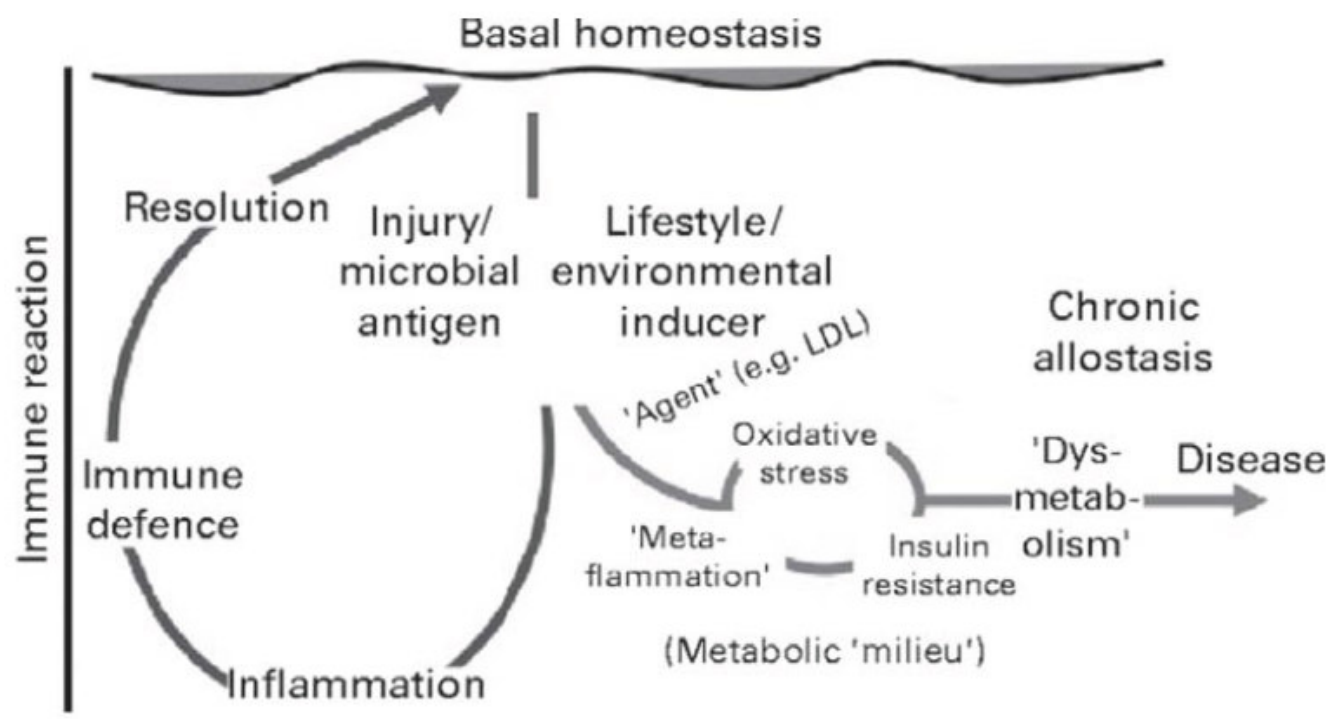

\author{
B. Modern, chronic, \\ Non-infectious response
}

Figure 2. A graphical representation of the difference between classical inflammation initiated by a microbial antigen or injury and metaflammation caused by lifestyle or environmental inducers (Adapted with permission from Egger G et al., Cambridge University Press 2009). 
activating inflammatory pathways and inducing insulin resistance (79). Paradoxically, there are also similar proinflammatory effects of both inactivity (80) and excessive exercise (81), suggesting a healthy range of certain lifestyle actions, above or below which there is a negative metabolic outcome.

On the assumption that metaflammation is triggered by an immune reaction, this would suggest that while human subjects have psychologically adopted the modern techno-industrial environment with relish, they have not yet successfully adapted to this physiologically. This implies that obesity may often be an accomplice to, as much as an offender in, major metabolic disease. The real (albeit distal) cause of such a disease appears to lie in aspects of the modern techno-industrial environment driving unhealthy lifestyle behaviors. If true, this suggests that while individual weight loss may be a component of chronic disease management, it may be neither 'necessary' nor 'sufficient' to reduce the problem at a population level. Greater multidisciplinary and policy input is needed to modify the economic and political drivers of the modern, obesogenic environment (66).

Nonalcoholic fatty liver disease (NAFLD) is a strong risk factor for insulin resistance, nonalcoholic steatohepatitis, and dyslipidemia, independent of visceral adiposity (82). Many of the signaling pathways involved in both inflammation and metabolism are elevated in steatotic liver (e.g., JNK, TLR4, ER stress). Similar to the effects of obesity on adipose tissue, NAFLD is associated with an increase in M1/Th1 cytokines and quantitative increases in immune cells (83-85). In addition, modulation of PPAR $\delta$-dependent M2 polarization pathways protects mice from NAFLD $(86,87)$. These effects may be mediated via Kupffer cells resident in the liver or by unique cell populations recruited to the liver with obesity (88).

Relevant to type 2 diabetes is the demonstration that inflammation in pancreatic islets can reduce insulin secretion and trigger $\beta$ cell apoptosis leading to decreased islet mass, critical events in the progression to diabetes $(89,90)$. The mediators of these effects are multifactorial and likely involve cytokines produced by $\beta$ cells themselves (91).

Multiple signaling pathways participate in translating obesity-derived nutrient and inflammatory signals into a cellular response relevant in disease. These include proinflammatory and antiinflammatory signals from the cell surface that integrate through many common intracellular pathways to generate the coordinated increase in inflammatory genes while repressing genes important in maintaining proper nutrient metabolism (15)
Immunometabolism is an emerging field of investigation at the interface between the historically distinct disciplines of immunology and metabolism. Accelerating interest in this area is being fuelled by the obesity epidemic and the relatively recent realization that obesity affects the immune system and promotes inflammation, and that obesity-induced inflammation potentially promotes a variety of chronic conditions and diseases (92). Immune response and metabolic regulation are highly integrated and the proper function of each is dependent on the other. This interface can be viewed as a central homeostatic mechanism, dysfunction of which can lead to a cluster of chronic metabolic disorders, particularly obesity, type 2 diabetes and cardiovascular disease. Collectively, these diseases constitute the greatest current threat to global human health and welfare (16).

\section{Nutrient Sensing and Metaflammation}

The integration of metabolism and immunity (or of nutrient-and pathogen-sensing pathways) can be traced back to an evolutionary need for survival, which resulted in the co-development of the organ systems and signaling pathways that mediate these two processes (16). The pressure to survive would have favored energy efficiency and storage to prepare for times of food deprivation and for mounting a potent immune response to defend the host against infectious agents. However, the initiation and maintenance of immunity is a metabolically costly endeavor and cannot operate efficiently under conditions of energy deficit $(93,94)$.

Therefore, immune defense is subject to a tradeoff between other energy-demanding processes, such as reproduction, thermoregulation and lactation.Interestingly, energy surplus (which is typical of individuals who are obese or suffer from metabolic syndrome) can also impair immune responses and induce chronic inflammation. Therefore, a balanced energy flux and maintenance of favorable metabolic homeostasis are required for the proper functioning of the immune system (95). It can be envisioned that a threat to the delicate balance between immune and metabolic responses, as can be induced by chronic nutrient deficiency or a continuous energy surplus, can transform this intimate, long-lasting and productive interaction into a pathological relationship 
The signaling pathways that sense and respond to three basic nutrients, free fatty acids, glucose and amino acids, are depicted. Many pathways that monitor nutrient availability, such as those of mammalian target of rapamycin (mTOR), insulin and nuclear transcription factors, and the unfolded-protein response (UPR) in the endoplasmic reticulum (ER), closely interact with each other. They also interact with inflammatory pathways, particularly those that are induced through the activation of IkB kinase- $\beta$ (IKK $\beta$ ) and JUN N-terminal kinase (JNK) (95).

As part of its role in integrating nutrient-sensing pathways with insulin signaling and survival pathways, the ER stress responses are also linked to the mTOR pathway (96) which regulates several processes in the cell, including energy metabolism. The proper functioning of the pathways that are involved in the sensing and management of nutrients is central to metabolic homeostasis and is therefore among the most fundamental requirements for survival.Metabolic systems are integrated with pathogen-sensing and immune responses, and these pathways are evolutionarily conserved. This close functional and molecular integration of the immune and metabolic systems is emerging as a crucial homeostatic mechanism, the dysfunction of which underlies many chronic metabolic diseases, including type 2 diabetes and atherosclerosis (95).

It is thus proposed that 'metaflammation, is to chronic disease, what classical inflammation is to injury or a microbial invasion, albeit with a different outcome, the latter leading usually to a resolution of disease, but the former leading to dysmetabolism, allostasis and chronic disease outcomes. Obesity, which is often proposed as the cause of such disease, may instead be often just an accomplice (97). The implications of such a finding are considered in relation to broader aspects of the environment, economic growth, policy change and current global financial issues (97).

\section{Inflammasome}

Traditionally, innate immunity has been viewed as the first line of defense discriminating "self" (e.g., host proteins) from "nonself" (e.g., microorganisms). However, emerging literature suggests that innate immunity actually serves as a sophisticated system for sensing signals of "danger," such as pathogenic microbes or host-derived signals of cellular stress, while remaining unresponsive to nondangerous motifs, such as normal host molecules, dietary antigens, or commensal gut flora. The notion that innate immunity functions as a danger sentinel has similarities to Matzinger's "danger hypothesis," proposed for adaptive immune responses (98). Such a model for recognizing situations of host danger allows for coordinate activation of immune system antimicrobial and tissue repair functions in response to infection or injury, while avoiding collateral damage in situations in which harmless nonself is present (17).

The innate immune system engages an array of germline- encoded pattern-recognition receptors (PRRs) to detect invariant microbial motifs. PRRs include the membrane-bound Toll-like receptors (TLRs) and C-type lectins (CTLs), which scan the extracellular milieu and endosomal compartments for pathogen-associated molecular patterns (PAMPs). A further set of intracellular PRRs, distinct from those described above, are the NOD-like receptors (NLRs) that recognize PAMPs as well as host-derived danger signals (danger-associated molecular patterns, DAMPs). PRRs that assemble into high-molecular weight, caspase-1-activating platforms called "inflammasomes" that control maturation and secretion of interleukins such as IL-1 $\beta$ and IL-18, whose potent proinflammatory activities direct host responses to infection and injury (99).

The NLRs comprise of 22 human genes. The NLR family is characterized by the presence of a central nucleotide-binding and oligomerization (NACHT) domain, which is commonly flanked by C-terminal leucine-rich repeats (LRRs) and $\mathrm{N}$-terminal caspase recruitment (CARD) or pyrin (PYD) domains. LRRs are believed to function in ligand sensing and autoregulation, whereas CARD and PYD domains mediate homotypic protein-protein interactions for downstream signaling. The NACHT domain, which is the only domain common to all NLR family members, enables activation of the signaling complex via ATP-dependent oligomerization.

Caspases are cysteine proteases that initiate or execute cellular programs, leading to inflammation or cell death. They are synthesized as inactive zymogens, and their potent cellular activities are tightly controlled by proteolytic activation. Caspases are categorized as either proinflammatory or proapoptotic, depending upon their participation in these cellular programs. The proinflammatory caspases comprise of caspase-1, -11 and -12 in mouse and caspase-1, -4 , and -5 in human (100). Of the proinflammatory caspases, caspase-1 is the most fully characterized. Its catalytic activity is tightly regulated by signal-dependent autoactivation within multiprotein complexes called "inflammasomes" that mediate caspase1 -dependent processing of cytokines such as IL-1 $\beta$ (101). 
IL-1 $\beta$ is an important proinflammatory mediator that is generated at sites of injury or immunological challenge to coordinate programs as diverse as cellular recruitment to a site of infection or injury and the regulation of sleep, appetite, and body temperature. IL-1 $\beta$ activity is rigorously controlled by expression, maturation, and secretion; proinflammatory stimuli induce expression of the inactive IL- $1 \beta$ proform, but cytokine maturation and release are controlled by inflammasomes.

Inflammasomes are assembled by self-oligomerizing scaffold proteins. A number of NLR family members have been reported to exhibit inflammasome activity in vitro; however, few NLR family members have clear physiological functions in vivo. NLRP1, NLRP3, and IPAF are danger sentinels that self-oligomerize via homotypic NACHTdomaininteractions to formhigh-molecularweight complexes (probably hexamers or heptamers) that trigger caspase-1 autoactivation. The NLRP3 inflammasome is currently the most fully characterized inflammasome and consists of the NLRP3 scaffold, the ASC (PYCARD) adaptor, and caspase-1. NLRP3 is activated upon exposure to whole pathogens, as well as a number of structurally diverse PAMPs, DAMPs, and environmental irritants. The unexpected finding that the NLRP3 inflammasome can be activated by host-derived molecules forms part of an emerging literature supporting a model in which the innate immune system detects endogenous indicators of cellular danger or stress, a hypothesis with similarities to the

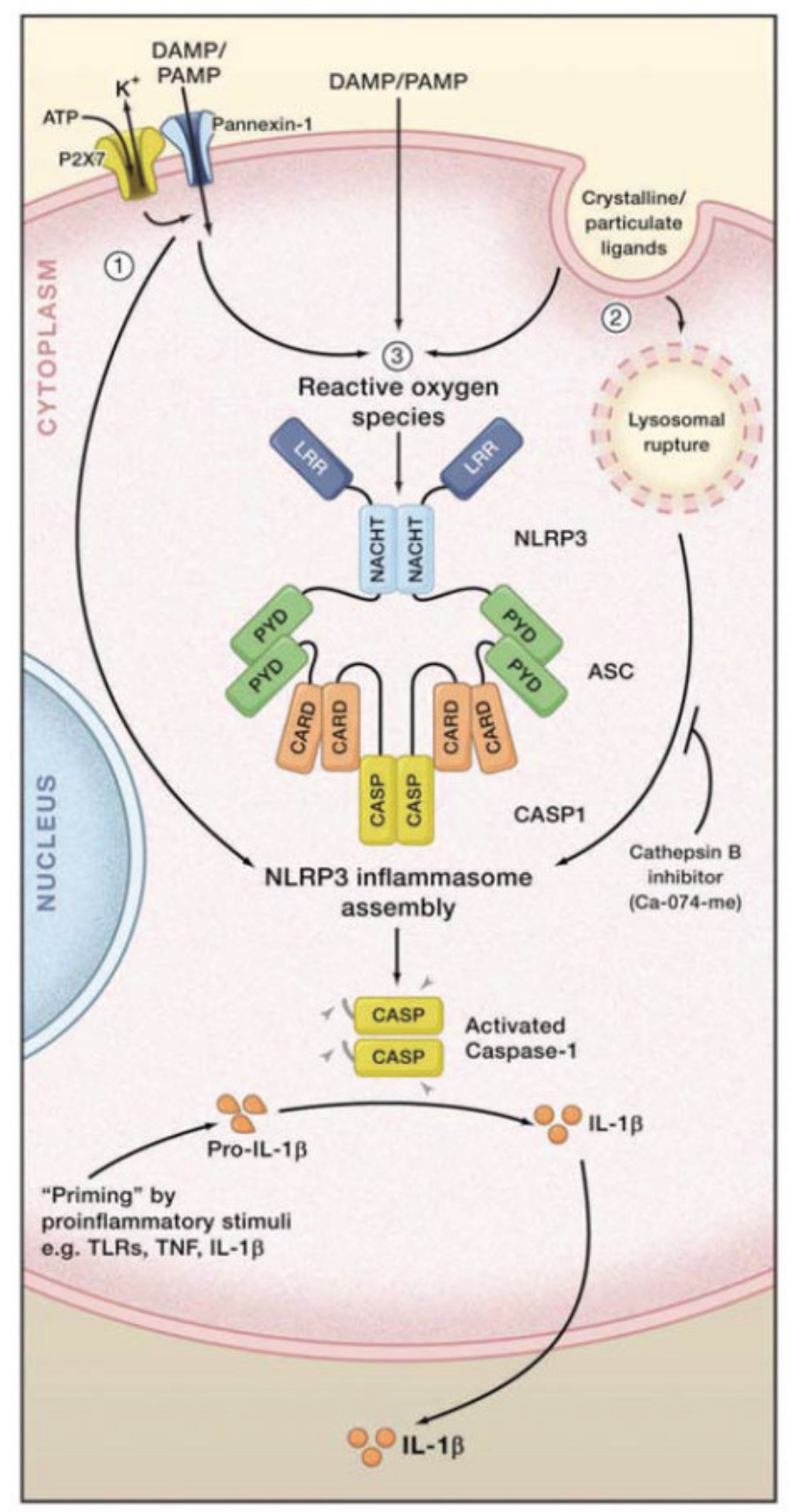

Figure 3. NLRP3 Inflammasome Activation (Adapted with permission from Schroder K et al., Elsevier Inc. 2010) 
"danger model" proposed for adaptive immune responses in place of the more simplistic self/nonself recognition model. The NLRP3 inflammasome also detects signs of metabolic stress, including elevated extracellular glucose (102) such as that occurring in metabolic syndrome, and monosodium urate (MSU) crystals that form as a consequence of hyperuricemia in the autoinflammatory disease gout (103).

The mammalian target of rapamycin complex 1 (mTORC1) pathway regulates cellular responses to fuel availability. Recent studies have demonstrated that within the central nervous system, and in particular the hypothalamus, mTORC1 represents an essential intracellular target for the actions of hormones and nutrients on food intake and body weight regulation. By being at the crossroads of a nutrient-hormonal signaling network, mTORC1 also controls important functions in peripheral organs, such as muscle oxidative metabolism, white adipose tissue differentiation and b-cell-dependent insulin secretion. Notably, dysregulation of the mTORC1 pathway has been implicated in the development of obesity and obesity-related conditions, such as type 2 diabetes (104). Hence, mTORC1 signaling is actually a critical mediator of cellular adaptation to nutrient overload and increased insulin demand during diet-induced obesity, which is a conclusion further confirmed by genetically inducing mTORC1 over activity within $\beta$-cells (105107).

The evidence reported so far clearly suggests that it might be counterproductive to broadly target the mTORC1 pathway for the treatment of obesity and obesityrelated metabolic alterations, such as hyperlipidemia, glucose intolerance and insulin resistance. This is due to the critical participation of the pathway in several aspects of energy balance regulation, from energy intake to energy storage and maintenance of appropriate intracellular responses to nutrient surfeit (104).

The recent finding that the NLRP3 inflammasome forms a nexus linking TXNIP, oxidative stress, and IL-1 $\beta$ production during metabolic stress provides new avenues for research and therapy for T2DM, a disease often described as the next global pandemic (108).

As noted by Vandanmagsar et al., the NLRP3 inflammasome is activated in adipose tissue in mouse models of obesity and attenuated by calorie restriction. It also correlates with glycemia in type 2 diabetes patients after weight loss interventions (109). Reactive oxygen species and mitochondria dysfunction in adipose tissue, which have been implicated in the cellular stress cascades leading to insulin resistance, are activating signals of the NLRP3 inflammasome (110). Others have shown that islet amyloid polypeptide in diabetic pancreas can activate NLRP3 inflammasome and induce IL- $1 \alpha$ secretion and inflammation of the islets, leading to the development of pancreatitis (111). Crystalline cholesterol present in atherosclerotic lesions has also been shown to be a potent activator of NLRP3, thereby participating in the inflammatory process present in atherosclerotic plaques (112). Two recent genome-wide association studies have identified associations between SNPs in the NLRP3 gene with high circulating levels of C-reactive protein and fibrinogen, two predictors of coronary heart disease $(113,114)$. Uric acid crystals involved in gout are also capable of activating NLRP3 (103). Moreover, uric acid and IL- $1 \alpha$ levels are both correlated with osteoarthritis progression and pathology (115), suggesting a role of the NLRP3 inflammasome. Finally, in diabetic nephropathy, local IL- $1 \alpha$ secretion has been shown to participate in the onset of kidney inflammation, and NLRP3 inflammasome activation is observed in chronic kidney disease (116,117).

It is not clear if the most common danger signals that are elevated with obesity, such as changes in nutrient metabolism $(118,119)$, mitochondria dysfunction (120), and endoplasmic reticulum stress $(121,122)$ require the NLRP3 inflammasome to promote insulin resistance. It also remains to be determined if insulin resistance itself can activate the NLRP3 inflammasome, therefore creating one of many vicious cycles involved in the insulin resistance/ inflammation axis (19).

\section{Adipokines in Metaflammation}

Adipose tissue was traditionally considered to be a longterm energy storage organ, but it is now appreciated that it has a key role in the integration of systemic metabolism. This metabolic function is mediated, in part, by its ability to secrete numerous proteins. Factors that are secreted by adipose tissue are collectively referred to as adipokines $(123,124)$. Importantly, following the onset of obesity, the secretory status of an adipose tissue depot can be modified by changes in the cellular composition of the tissue, including alterations in the number, phenotype and localization of immune, vascular and structural cells. The expression of adipokines can also vary depending on the site of an adipose tissue depot. The two most abundant depots are visceral and subcutaneous adipose tissues, which produce unique profiles of adipokines $(125,126)$. 
In some instances, it has been shown that high-calorie diets can promote the development of a pro-inflammatory state in these depots in a similar manner to that observed in subcutaneous and visceral adipose tissue (127). Although the functional importance of many of these individual adipose depots is generally not known, recent evidence suggests that diet-induced changes in their adipokine secretion can influence the function of the associated tissue (128).

Most adipokines stimulate inflammatory responses, are upregulated in obesity and promote obesity-induced metabolic and cardiovascular diseases. Collectively, these findings have led to the notion that metabolic dysfunction that is due to excess adipose tissue mass may partly result from an imbalance in the expression of proand anti-inflammatory adipokines, thereby contributing to the development of obesity-linked complications. Accordingly, the concept that adipokines function as regulators of body homeostasis has received widespread attention from the research community (129).

The production of most adipokines is upregulated in the obese state, and these pro-inflammatory proteins typically function to promote obesity-linked metabolic diseases. In addition to leptin, TNF and IL-6, more recently identified adipokines that promote inflammation include resistin, retinol-binding protein 4 (RBP4), lipocalin 2, IL-18, angiopoietin-like protein 2 (ANGPTL2), CCchemokine ligand 2 (CCL2), CXC-chemokine ligand 5 (CXCL5) and nicotinamide phosphoribosyltransferase (NAMPT) (129).

In addition to the numerous pro-inflammatory adipokines described above, adipose tissues also secrete a smaller number of anti-inflammatory factors, such as adiponectin, which has been the subject of intense investigation $(123,124)$, and secreted frizzeled-related protein 5 (sFRP5), which has been recently identified as an adipokine (130).

Adipose tissues can influence and communicate with many other organs, including the brain, heart, vasculature, liver and muscle, through the production of various secretory factors or adipokines. Adipokines have both pro-inflammatory and anti-inflammatory activities, and the balance between the different factors is crucial for determining homeostasis throughout the body based on nutritional status. when adipocyte dysfunction occurs as a result of adipose tissue expansion (which may be due to over-nutrition or physical inactivity, for example), dysregulation of adipokine production can have local or systemic effects on inflammatory responses, thereby contributing to the initiation and progression of obesityinduced metabolic and cardiovascular complications.
Therapeutic strategies that counteract the imbalance of pro-inflammatory and anti-inflammatory adipokines could be an attractive and useful means for preventing and/or treating obesity-related metabolic and cardiovascular diseases (129).

\section{Endoplasmic Retikulum Stress in Metaflammation}

It is increasingly important to understand how excess adiposity can perturb normal metabolic functions. It is now clear that this disruption involves not only pathways controlling lipid and glucose homeostasis but also integration of metabolic and immune response pathways. Under conditions of nutritional excess, this integration can result in a metabolically driven, low-grade, chronic inflammatory state, referred to as "metaflammation," that targets metabolically critical organs and tissues to adversely affect systemic homeostasis. Endoplasmic reticulum dysfunction is another important feature of chronic metabolic disease that is also linked to both metabolic and immune regulation (131).

Recent studies have suggested that ER-mediated stress signaling and adaptation pathways (referred to as the unfolded protein response [UPR]) are also activated under obese conditions and can mediate both metabolic and immune responses (132). The UPR consists of 3 main branches controlled by the ER membrane proteins inositol-requiring enzyme (IRE)-1, protein kinase-like ER kinase (PERK), and activating transcription factor (ATF) $\alpha$. In response to changes in the protein-folding status within the ER, these proteins activate distinct and sometimes overlapping pathways. The UPR has also been shown to induce autophagy, which is important in organelle maintenance and recycling and likely aids in the degradation of misfolded proteins (133). Activation of these adaptive responses serves to induce signaling and transcriptional events that reestablish ER homeostasis, or induce apoptosis if the stress cannot be resolved. In this manner, the UPR maintains protein integrity during fluctuations in various environmental and cellular conditions.

Studies have demonstrated that improper functioning of the UPR plays an important role in chronic metabolic diseases, including obesity, insulin resistance, and diabetes (122). Specifically, obesity results in increased ER stress, particularly in the liver and adipose tissue of mice. (132) 
Evidence also suggests that ER stress is important for $\beta$-cell development and survival. One mechanism by which ER stress has been proposed to negatively impact metabolic homeostasis is through induction of inflammatory signaling networks. Indeed, all 3 arms of the UPR can activate JNK and/or NF- $\chi \mathrm{B}$ signaling, as well as potentially other pathways. This signaling has been proposed to result in subsequent inhibition of insulin action via IRS-1 phosphorylation, although other mechanisms are also possible. Moreover, increased JNK and NF- $x \mathrm{~B}$ signaling would be expected to induce other inflammatory mediators that are associated with metabolic disease. In addition, ER stress-mediated regulation of autophagy could play a role in modulation of inflammatory pathways because autophagy has been implicated in immune cell function at multiple levels $(17,134,135)$. Although this remains to be definitively proven, it supports the idea that ER stress may be at least a contributing factor to the lowgrade inflammation observed in obesity.

Metabolic, inflammatory, and ER stress response pathways are important energy-regulating pathways that are tightly integrated. In addition, factors such as PKR, TLRs, and nuclear receptors (NRs) serve to sense, direct, and modulate signaling through these central pathways. The result is a complex, highly interconnected network that acts in combination to maintain metabolic equilibrium in response to fluctuating energy levels and demands. Stressors, such as the nutritional overabundance prevalent in modern society, can act to disturb the balance between these pathways, ultimately leading to disease (131).

Thus, metaflammation and ER dysfunction are emerging as critical processes that, if successfully targeted therapeutically, have the potential to shift the tipping point, strengthen overall adaptive capacity, and improve various metabolic parameters. Indeed, encouraging results have been obtained in both preclinical and clinical studies for targeting these pathways to treat chronic metabolic diseases (131).

Hepatic Steatosis as an Inflammatory Disease

Non-alcoholic fatty liver disease (NAFLD) is currently the most common form of chronic liver disease and is strongly associated with obesity, type 2 diabetes and insulin resistance $(136,137)$. As such, NAFLD is now considered as the hepatic manifestation of the metabolic syndrome. NAFLD encompasses a wide spectrum ranging from simple triglyceride (TG) accumulation in hepatocytes (hepatic steatosis) to hepatic steatosis with inflammation (steatohepatitis), fibrosis, cirrhosis and in severe cases, hepatocarcinoma (138).

Steatosis occurs when there is an imbalance between lipid availability and lipid disposal (via fatty acid oxidation or VLDL secretion). In physiological conditions, the potential sources of fatty acids that contribute to fatty liver development are non-esterified fatty acids coming from the hydrolysis of TGs stored in the adipose tissue, dietary fatty acids arising from uptake and metabolism of intestinal chylomicrons and newly fatty acids synthesized through de novo lipogenesis in the liver.

Lipogenesis is an insulin-and glucose-dependent process that is under the control of specific transcription factors, sterol regulatory element binding protein $1 \mathrm{c}$ (SREBP-1c), activated by insulin and carbohydrate response element binding protein (ChREBP) activated by glucose. Insulin induces the maturation of SREBP-1c by a proteolytic mechanism initiated in the endoplasmic reticulum (ER). SREBP-1c in turn activates glycolytic gene expression, allowing glucose metabolism, and lipogenic genes in conjunction with ChREBP.

The ER stress activates the cleavage of SREBP-1c independent of insulin, thus explaining the paradoxical stimulation of lipogenesis in an insulin-resistant liver. Inhibition of the ER stress in obese rodents decreases SREBP-1c activation and lipogenesis and improves markedly hepatic steatosis and insulin sensitivity. ER is thus a new partner in steatosis and metabolic syndrome (139).

Chronic overfeeding might induce hepatic injury if adipose tissue expandability is inadequate. In such a condition, adipose tissue is characterised by an increased presence of ER-stressed hypertrophic adipocytes. ER stress activates apoptotic and inflammatory pathways in hypertrophic adipocytes, and these, in turn, activate signalling pathways that amplify the inflammatory response and extend it throughout the adipose tissue. The above events lead to IR in adipose tissue with a consequent increase in lipolysis and a decrease in liposynthesis. The resulting increase in the serum levels of FFAs and lipids, the strongly compromised secretion of adiponectin and leptin resistance trigger an excessive hepatic lipid accumulation and an increased presence of ER-stressed steatotic hepatocytes.

Chronically ER-stressed hepatocytes, in addition to being insulin resistant, activate inflammatory and apoptotic pathways. The activated inflammatory pathways release chemokines and cytokines, which will elicit an increased influx of Kupffer Cells (KCs) and Hepatic Stellate 
Cells (HSCs) around dying hepatocytes. Dying or dead hepatocytes are eliminated by macrophage activity, which is affected mainly by activated KCs. Upon the release of chemokines by dying hepatocytes and activated $\mathrm{KCs}$, HSCs acquire an MFB-like migratory phenotype that is characterised by the secretion of fibrogenic cytokines and interacting matrix components. Some of these cytokines may stimulate myofibroblasts (MFBs) (in an autocrine manner) and HSCs (in a paracrine manner), thereby perpetuating the fibrogenic process (140).

Type 2 Diabetes as an Inflammatory Disease

The leading hypothesized mechanisms to explain insulin resistance and islet $\beta$-cell dysfunction in T2D have been oxidative stress, ER stress, amyloid deposition in the pancreas, ectopic lipid deposition in the muscle, liver and pancreas, and lipotoxicity and glucotoxicity. All of these stresses can be caused by overnutrition (141145), although it has been difficult to determine which mechanism is the most important in each tissue and in each model or individual with T2D. It is noteworthy, however, that each of these cellular stresses is also thought to either induce an inflammatory response or to be exacerbated by or associated with inflammation (95,146-149).

Cross-sectional and prospective studies have described elevated circulating levels of acute-phase proteins (such as CRP), haptoglobin, fibrinogen, plasminogen activator inhibitor and serum amyloid A) and sialic acid, as well as cytokines and chemokines, in patients with T2D (150153). Furthermore, elevated levels of interleukin- $1 \beta$ (IL-1 $\beta)$, IL-6 and CRP are predictive of T2D $(151,154)$. Similarly, the serum concentration of IL-1 receptor antagonist (IL-1RA) is elevated in obesity and prediabetes, with an accelerated increase in IL-1RA levels before the onset of T2D $(153,155,156)$. The expression of IL-1RA is induced by IL- $1 \beta$ and reflects the body's response to counterbalance increased IL-1 $\beta$ activity.

Elevated levels of circulating IL- $1 \beta$, IL- 6 and acutephase proteins in T2D may reflect the activation of innate immune cells by increased nutrient concentrations, but the levels of these inflammatory markers may not necessarily reflect the degree of inflammation in individual tissues (157).

The underlying mechanisms of 'nutrient' (that is, glucose and FFA)-induced activation of IL- $1 \beta$ are complex. FFAs may stimulate the production pro-inflammatory molecules by direct activation of TLR 2 and TLR4, which can sense lipids, or indirectly through FFA metabolites such as ceramide (158-161). Glucose-induced IL- $\beta$ production is thought to involve the NLRP3 inflammasome. High concentrations of glucose induce the dissociation of thioredoxin-interacting protein (TXNIP) from thioredoxin under the influence of reactive oxygen species, allowing binding of TXNIP to the NLRP3 inflammasome. This leads to the activation of caspase 1 and the subsequent processing of pro-IL-1 $\beta$ and release of mature IL-1 $\beta$ (104). Whether reactive oxygen species are indispensable in this process remains unclear. $\beta$-cells have very low levels of antioxidative enzymes and are therefore particularly vulnerable to oxidative stress; however, activation of the inflammasome in the absence of reactive oxygen species has been shown in patients with chronic granulomatous disease (162-166). Interestingly, deposition of amyloid in the islets is a hallmark of T2D, and human IAPP seems to contribute to the induction of IL- $1 \beta$ production in the islets through the NLRP3 inflammasome (149).

It remains possible that the inflammasome may act as a sensor of metabolic danger (108), resulting in IL$1 \beta$ production and the induction of numerous cytokines and chemokines (164-166). Therefore, activation of the inflammasome may contribute to the recruitment of immune cells, which can mediate a broad inflammatory response. These initial mechanisms of IL- $1 \beta$ induction may be amplified by a cycle of autoinflammation. Indeed, human islets, particularly purified human $\beta$-cells, are very sensitive to IL-1 $\beta$ autostimulation (167). This is probably a consequence of the abundant expression of IL-1 receptor type 1 (IL-1R1) by these cells.

IL- $1 \beta$ autostimulation of islets can be prevented by reducing NF-kB activity or by blocking IL-1R1 signalling (with IL-1RA, by ligand neutralization or by the genetic elimination of the IL-1R1-associated signal- ling protein myeloid differentiation primary-response protein 88 (MyD88) (84,85). Blocking IL-1R1 signalling also inhibits FFA- and glucose-induced upregulation of IL-1 $\beta$ (167-168).

In summary, multiple mechanisms may contribute to inflammation in T2D, some of which are general and the others are tissue specific. Thus, in the pancreatic islet cells inflammation may be initiated by direct sensing of excess nutrients, leading to activation of the IL-1 system, whereas in adipose tissue, excess storage of fat causes hypoxia and inflammation. Common downstream mechanisms include the activation of NF-kB and JNK pathways and cytokine and chemokine release, leading to the recruitment of immune cells. Current anti-inflammatory approaches to treating T2D focus on salsalate and IL-1 $\beta$ antagonism 
(Anakinra). Mechanistically these approaches may have similarities, including the modulation of IL-1R1 and NF$\varkappa$ B pathways (157).

\section{Conclusions}

Energy and nutrient management in all organisms requires the highly regulated and coordinated operation of many homeostatic systems. Much of the development and evolution of these systems has taken place in the absence of pressures that we now experience as modern humans, including excess nutrients, new dietary components, lack of physical activity, and an increased life span. In fact, the requirements for the duration as well as the magnitude of adaptive responses have dramatically increased due to both increases in life expectancy and a chronic lifetime exposure to the stress signals associated with caloric excess. Consequently, biological responses are unable to cope with these challenges and homeostatic systems gradually deteriorate, giving rise to an array of pathologies.

Thus, it has become essential to understand the mechanisms that regulate energy balance and peripheral metabolism identity possible therapeutic targets that will halt obesity and its disastrous metabolic consequences.

\section{References:}

1. World Health Organization. Obesity and overweight. WHO Website. http://www.who.int/mediacentre/factsheets/fs311/ en/. Updated March 2011.

2. Finucane MM, Stevens GA, Cowan MJ, Danaei G, Lin JK, Paciorek CJ, et al. Global Burden of Metabolic Risk Factors of Chronic Diseases Collaborating Group (Body Mass Index). National, regional, and global trends in bodymass index since 1980: systematic analysis of health examination surveys and epidemiological studies with 960 country-years and 9.1 million participants. Lancet. 2011; 377: 557-67.

3. de Onis M, Blössner M, Borghi E. Global prevalence and trends of overweight and obesity among preschool children. Am J Clin Nutr. 2010; 92: 1257-64.

4. Wing RR. Changing diet and exercise behaviors in individuals at risk for weight gain. Obes Res. 1995; 3: 277-82.

5. Sacks FM, Bray GA, Carey VJ, Smith SR, Ryan DH, Anton $\mathrm{SD}$, et al. Comparison of weight-loss diets with different compositions of fat, protein, and carbohydrates. N Engl J Med. 2009; 360: 859-73.

6. Malik VS, Popkin BM, Bray GA, Després JP, Hu FB. Sugarsweetened beverages, obesity, type 2 diabetes mellitus, and cardiovascular disease risk. Circulation. 2010; 121 : 1356-64.

7. Gross LS, Li L, Ford ES, Liu S. Increased consumption of refined carbohydrates and the epidemic of type 2 diabetes in the United States: an ecologic assessment. Am J Clin Nutr. 2004; 79: 774-9.
8. Bray GA. Soft drink consumption and obesity: it is all about fructose. Curr Opin Lipidol. 2010; 21: 51-7.

9. Kestens $Y$, Daniel M. Social inequalities in food exposure around schools in an urban area. Am J Prev Med. 2010; 39: $33-40$.

10. Berrington de Gonzalez A, Hartge P, Cerhan JR, Flint AJ, Hannan L, et al. Body-mass index and mortality among 1.46 million white adults. N Engl J Med. 2010; 363: 2211-9.

11. Flegal KM, Graubard BI, Williamson DF, Gail MH. Causespecific excess deaths associated with underweight, overweight, and obesity. JAMA. 2007; 298: 2028-37.

12. Zheng W, McLerran DF, Rolland B, Zhang $X$, Inoue M, Matsuo $\mathrm{K}$, et al. Association between body-mass index and risk of death in more than 1 million Asians. N Engl J Med. 2011; 364: 719-29.

13. Hevener AL, Febbraio MA, Stock Conference Working Group. The 2009 Stock Conference Report: Inflammation, Obesity and Metabolic Disease. Obes Rev 2010, 11: 635-44.

14. Spencer M, Yao-Borengasser A, Unal R, Rasouli N, Gurley CM, Zhu B, et al. Adipose tissue macrophages in insulinresistant subjects are associated with collagen $\mathrm{VI}$ and fibrosis and demonstrate alternative activation. Am J Physiol Metab. 2010; 299: E1016-27.

15. Lumeng $C N$, Saltiel AR. Inflammatory links between obesity and metabolic disease. J Clin Invest 2011; 11: 2111-7.

16. Hotamisligil GS. Inflammation and metabolic disorders. Nature. 2006; 444: 860-7.

17. Schroder K, Tschopp J. The Inflammasomes. Cell 2010; 140: 821-32.

18. Horng $T$, Hotamisligil GS. Linking the inflammasome to obesity -related disease. Nat Med 2011; 17: 164-5.

19. Mori MA, Bezy O, Kahn CR. Metabolic syndrome: Is Nlrp3 inflammasome a trigger or a target of insulin resistance? Circ Res 2011; 108: 1160-2.

20. Weiss R. Fat distribution and storage: how much, where, and How? Eur J Endocrinol 2007; 157: S39-45.

21. Frayn KN. Adipose tissue as a buffer for daily lipid flux. Diabetologia 2002; 45: 1201-10.

22. Wajchenberg BL. Subcutaneous and visceral adipose tissue: their relation to the metabolic syndrome. Endocr Rev 2000; 21: $697-708$

23. Arner P. Introduction: the inflammation orchestra in adipose tissue. J Int Med 2007; 262: 404-7.

24. Yang X, Smith U. Adipose tissue distribution and risk of metabolic disease: does thiazolidinedione-induced adipose tissue redistribution provide a clue to the answer? Diabetologia 2007; 50: 1127-39.

25. Rocha VZ, Libby P. The multiple facets of the fat tissue. Thyroid 2008; 18: 175-83.

26. Berg $\mathrm{AH}$, Scherer PE. Adipose tissue, inflammation and cardiovascular disease. Circ Res 2005; 96: 939-49.

27. Bergman RN, Kim SP, Catalano KJ, Hsu IR, Chiu JD, Kabir M, et al. Why visceral fat is bad: mechanisms of the metabolic syndrome. Obesity 2006; 14 (Suppl. Feb.): 16S-9.

28. Hamdy O, Porramatikul S, Al-Ozairi E. Obesity: the paradox between visceral and subcutaneous fat. Curr Diab Rev 2006; 2: 1-7.

29. Wiklund P, Toss F, Weinehall L, Hallmans G, Franks PW, Nordstrom A, et al. Abdominal and gynoid fat mass are associated with cardiovascular risk factors in men and women. J Clin Endocrinol Metab 2008; 93: 4360-6.

30. Karelis AD, St-Pierre DH, Conus F, Rabasa-Lhoret R, Poehlman ET. Metabolic and body composition factors in sub-groups of obesity: what do we know? J Clin Endocrinol Metab 2004; 89: 2569-75.

31. Cancello R, Tordjman J, Poitou C, Guilhem G, Bouillot JL, Hugol $D$, et al. Increased infiltration of macrophages in omental 
adipose tissue is associated with marked hepatic lesions in morbid human obesity. Diabetes 2006; 55: 1554-61.

32. Goodarzi MT, Varmaziar L, Navidi AA, Parivar K. Study of oxidative stress in type 2 diabetic patients and its relationship with glycated hemoglobin. Saudi Med J 2008; 29: 503-6.

33. Saltevo J, Laakso M, Jokelainen J, Keinanen-Kiukaanni S, Kumpusalo E, Vanhala M. Levels of adiponectin, C-reactive protein and interleukin-1 receptor antagonist are associated with insulin sensitivity: a population-based study. Diabetes Metab Res Rev 2008; 24: 378-83.

34. Libby P. Inflammatory mechanisms: the molecular basis of inflammation and disease. Nutr Rev 2007; 65: S140-S146.

35. Hotamisligil GS, Shargill NS, Piegelman BM. Adipose expression of tumor necrosis factor-alpha: direct role in obesity-linked insulin resistance. Science 1993; 259: 87-91.

36. Egger G, Dixon J. Should obesity be the main game? Or do we need an environmental makeover to combat the inflammatory and chronic disease epidemics? Obes Rev 2009; 10: 237-49.

37. Nathan C. Epidemic inflammation: pondering obesity. Mol Med 2008; 14: 485-92.

38. Sun K, Scherer PE. Adipose Tissue Dysfunction: A Multistep Process. Berlin, Germany: Springer-Verlag Berlin Heidelberg; 2010: 67-75.

39. Sun K, Kusminski CM, Scherer PE. Adipose tissue remodeling and obesity. J Clin Invest 2011; 121: 2094-101.

40. Gordon S. The macrophage. Bioessays. 1995;17: 977-86.

41. Cinti S, Mitchell G, Barbatelli G, Murano I, Ceresi E, Faloia E, et al. Adipocyte death defines macrophage localization and function in adipose tissue of obese mice and humans. J Lipid Res. 2005; 46: 2347-55.

42. Nishimura S, Manabe I, Nagasaki M, Hosoya $Y$, Yamashita $\mathrm{H}$, Fujita $\mathrm{H}$, et al. Adipogenesis in obesity requires close interplay between differentiating adipocytes, stromal cells, and blood vessels. Diabetes. 2007; 56: 1517-26.

43. Nishimura S, Manabe I, Nagasaki M, Seo K, Yamashita H, Hosoya $\mathrm{Y}$, et al. In vivo imaging in mice reveals local cell dynamics and inflammation in obese adipose tissue. $\mathrm{J}$ Clin Invest. 2008;118: 710-21.

44. Strissel KJ, Stancheva Z, Miyoshi H, Perfield JW 2nd, DeFuria $\mathrm{J}$, Jick Z, et al. Adipocyte death, adipose tissue remodeling, and obesity complications. Diabetes. 2007; 56: 2910-8.

45. Lumeng CN, Deyoung SM, Bodzin JL, Saltiel AR. Increased inflammatory properties of adipose tissue macrophages recruited during diet-induced obesity. Diabetes. 2007; 56: 16-23.

46. Kanda H, Tateya S, Tamori Y, Kotani K, Hiasa K, Kitazawa R, et al. MCP-1 contributes to macrophage infiltration into adipose tissue, insulin resistance, and hepatic steatosis in obesity. J Clin Invest. 2006; 116: 1494-505.

47. Weisberg SP, Hunter D, Huber R, Lemieux J, Slaymaker S, Vaddi $\mathrm{K}$, et al. CCR2 modulates inflammatory and metabolic effects of high-fat feeding. J Clin Invest. 2006; 116: 115-24.

48. Xu H, Barnes GT, Yang Q, Tan G, Yang D, Chou CJ, et al. Chronic inflammation in fat plays a crucial role in the development of obesity-related insulin resistance. J Clin Invest. 2003; 112: 1821-30.

49. Nara N, Nakayama $Y$, Okamoto $S$, Tamura H, Kiyono M, Muraoka $\mathrm{M}$, et al. Disruption of CXC motif chemokine ligand-14 in mice ameliorates obesity-induced insulin resistance. J Biol Chem. 2007; 282: 30794-803.

50. Trayhurn P, Wood IS. Adipokines: inflammation and the pleiotropic role of white adipose tissue. Br J Nutr. 2004; 92 : 347-55.

51. Halberg N, Khan T, Trujillo ME, Wernstedt-Asterholm I, Attie AD, Sherwani S, et al. Hypoxia-inducible factor 1 alpha induces fibrosis and insulin resistance in white adipose tissue. Mol
Cell Biol. 2009; 29: 4467-83.

52. Hosogai N, Fukuhara A, Oshima K, Miyata Y, Tanaka S, Segawa $\mathrm{K}$, et al. Adipose tissue hypoxia in obesity and its impact on adipocytokine dysregulation. Diabetes. 2007;56: 90111.

53. Ye J, Gao Z, Yin J, He Q. Hypoxia is a potential risk factor for chronic inflammation and adiponectin reduction in adipose tissue of ob/ob and dietary obese mice. Am J Physiol Endocrinol Metab. 2007; 293: E1118-28.

54. Chen B, Lam KS, Wang Y, Wu D, Lam MC, Shen J, et al. Hypoxia dysregulates the production of adiponectin and plasminogen activator inhibitor-1 independent of reactive oxygen species in adipocytes. Biochem Biophys Res Commun. 2006; 341: 549-56.

55. Lolmede K, Durand de Saint Front V, Galitzky J, Lafontan M, Bouloumie A. Effects of hypoxia on the expression of proangiogenic factors in differentiated 3T3-F442A adipocytes. Int J Obes Relat Metab Disord. 2003; 27: 118795.

56. Shi H, Kokoeva MV, Inouye K, Tzameli I, Yin H, Flier JS. TLR4 links innate immunity and fatty acid-induced insulin resistance. J Clin Invest. 2006; 116: 3015-25.

57. Suganami T, Nishida J, Ogawa Y. A paracrine loop between adipocytes and macrophages aggravates inflammatory changes: role of free fatty acids and tumor necrosis factor alpha. Arterioscler Thromb Vasc Biol. 2005; 25: 2062-68.

58. Nguyen MT, Satoh H, Favelyukis $\mathrm{S}$, Babendure JL, Imamura T, Sbodio Jl, et al. JNK and tumor necrosis factor-alpha mediate free fatty acid-induced insulin resistance in 3T3-L1 adipocytes. J Biol Chem. 2005; 280: 35361-71.

59. Lumeng CN, Bodzin JL, SaltielAR. Obesity induces a phenotypic switch in adipose tissue macrophage polarization. $\mathrm{J}$ Clin Invest. 2007;117: 175-84.

60. Kosteli A, Sugaru E, Haemmerle G, Martin JF, Lei J, Zechner R, et al. Weight loss and lipolysis promote a dynamic immune response in murine adipose tissue. J Clin Invest. 2010; 120: 3466-79.

61. Shoelson SE. Banking on ATM as a new target in metabolic syndrome. Cell Metab. 2006; 4: 337-8

62. Conde J, Gomez R, Scotece M, Bianco G, Lago F, Gualillo O. Adipocytes and macrophages: two engines powering inflammation in obesity and its complications. Obes Metabolism 2010; 6: 5-9.

63. Suganami T, Ogawa Y. Adipose tissue macrophages: their role in adipose tissue remodeling. J Leukoc Biol 2010; 88: 33-9.

64. Mantovani A, Allavena P, Sica A, Balkwill F. Cancer related inflammation. Nature 2008; 454: 436-44.

65. Medzhitov R Origin and physiological roles of inflammation. Nature 2008; 454: 428-35.

66. Egger G, Dixon J. Obesity and chronic disease: always offender or often just accomplice? Br J Nutr 2009; 102: 1238-42.

67. Hajer GR, van Haeften TW, Visseren FLJ Adipose tissue dysfunction in obesity, diabetes, and vascular diseases. Eur Heart J 2008; 9, 2959-71.

68. O'Keefe JH, Bybee KA, Lavie CJ Alcohol and cardiovascular health: the razor-sharp double-edged sword. J Am Coll Cardiol 2007; 50: 1009-14.

69. Solinas G, Vilcu C, Neels JG, Bandyopadhyay GK, Luo JL, Naugler W, et al. JNK1 in hematopoietically derived cells contributes to diet-induced inflammation and insulin resistance without affecting obesity. Cell Metab 2007; 6: 386-97.

70. Esmaillzadeh A, Kimiagar M, Mehrabi Y, Azadbakht L, Hu FB, Willett WC. Dietary patterns and markers of systemic inflammation among Iranian women. J Nutr 2007; 137: 9928.

71. Haversen L, Danielsson KN, Fogelstrand L, Wiklund O. Induction of proinflammatory cytokines by long-chain saturated fatty 
acids in human macrophages. Atherosclerosis 2009; 202: 382-93.

72. Harvey KA, Arnold T, Rasool T, Antalis C, Miller SJ, Siddiqui RA. Trans-fatty acids induce pro-inflammatory responses and endothelial cell dysfunction. Br J Nutr 2008; 99: 723-31.

73. Rayssiguier Y, Gueux E, Nowacki W, Rock E, Mazur A. High fructose consumption combined with low dietary magnesium intake may increase the incidence of the metabolic syndrome by inducing inflammation. Magnes Res 2006; 19: 237-43.

74. Dickinson S, Hancock DP, Petocz P, Ceriello A, Brand-Miller J. High-glycemic index carbohydrate increases nuclear factorkappaB activation in mononuclear cells of young, lean healthy subjects. Am J Clin Nutr 2008; 87: 1188-93.

75. Simpson N, Dinges DF Sleep and inflammation. Nutr Rev 2007; 65: S244-52.

76. Thorley AJ, Tetley TD Pulmonary epithelium, cigarette smoke, and chronic obstructive pulmonary disease. Int $\mathrm{J}$ Chron Obstruct Pulmon Dis 2007; 2: 409-28.

77. Kulmatycki KM, Jamali $F$ Drug disease interactions: role of inflammatory mediators in depression and variability in antidepressant drug response. J Pharm Pharm Sci 2006; 9: 292-306.

78. Hickling S, Hung J, Knuiman M, Divitini M, Beilby J. Are the associations between diet and $\mathrm{C}$-reactive protein independent of obesity? Prev Med 2008; 47: 71-6.

79. Watt MJ. Storing up trouble: does accumulation of intramyocellular triglyceride protect skeletal muscle from insulin resistance? Clin Exp Pharmacol Physiol 2009; 36: 5-11.

80. Hamburg NM, McMackin CJ, Huang AL, Shenouda SM, Widlansky ME, Schulz E, et al. Physical inactivity rapidly induces insulin resistance and microvascular dysfunction in healthy volunteers. Arterioscler Thromb Vasc Biol 2007; 27: 2650-6.

81. Neubauer O, Koenig D. Wagner KH Recovery after an Ironman triathlon: sustained inflammatory responses and muscular stress. Eur J Appl Physiol 2008; 104: 417-26.

82. Fabbrini E, Magkos F, Mohammed BS, Pietka T, Abumrad NA, Patterson BW, et al. Intrahepatic fat, not visceral fat, is linked with metabolic complications of obesity. Proc Natl Acad Sci U S A. 2009;106: 15430-5.

83. Li Z, Soloski MJ, Diehl AM. Dietary factors alter hepatic innate immune system in mice with non-alcoholic fatty liver disease. Hepatology. 2005; 42: 880-5.

84. Kremer M, Hines IN, Mil ton RJ, Wheeler MD. Favored T helper 1 response in a mouse model of hepatosteatosis is associated with enhanced T cell- mediated hepatitis. Hepatology. 2006; 44: 216-27.

85. Baffy G. Kupffer cells in non-alcoholic fatty liver disease: the emerging view. J Hepatol. 2009; 51: 212-23.

86. Odegaard JI, Ricardo-Gonzalez RR, Red Eagle A, Vats D, Morel CR, Goforth MH, et al. Alternative M2 activation of Kupffer cells by PPARdelta ameliorates obesity-induced insulin resistance. Cell Metab. 2008; 7: 496-507.

87. Kang K, Reilly SM, Karabacak V, Gangl MR, Fitzgerald K, Hatano B, et al. Adipocyte-derived Th2 cytokines and myeloid PPARdelta regulate macrophage polarization and insulin sensitivity. Cell Metab. 2008;7: 485-95.

88. Obstfeld AE, Sugaru E, Thearle M, Francisco AM, Gayet C, Ginsberg HN, et al. C-C chemokine receptor 2 (CCR2) regulates the hepatic recruitment of myeloid cells that promote obesity-induced hepatic steatosis. Diabetes. 2010; 59: 916-25.

89. Ehses JA, Boni-Schnetzler M, Faulenbach M, Donath MY. Macrophages, cytokines and beta-cell death in Type 2 diabetes. Biochem Soc Trans. 2008; 36: 340-2.

90. Donath MY, Boni-Schnetzler M, Ellingsgaard H, Halban PA,
Ehses JA. Cytokine production by islets in health and diabetes: cellular origin, regulation and function. Trends Endocrinol Metab. 2010; 21: 261-7.

91. Maedler K, Sergeev P, Ris F, Oberholzer J, Joller-Jemelka HI, Spinas GA, et al Glucose-induced beta cell production of IL-1 beta contributes to glucotoxicity in human pancreatic islets. J Clin Invest. 2002; 110: 851-60.

92. Mathis K, Shoelson SE. Immunometabolism: an emerging frontier. Nat Rev Immunol 2011; 11: 81-3.

93. Demas GE, Chefer V, Talan MI, Nelson RJ. Metabolic costs of mounting an antigen-stimulated immune response in adult and aged C57BL/56J mice. Am. J. Physiol. 1997; 273: R1631-7.

94. Marti A, Marcos A, Martinez JA. Obesity and immune function relationships. Obes. Rev. 2001; 2: 131-40.

95. Hotamisligil GS, Erbay E. Nutrient sensing and inflammation in metabolic diseases. Nat Rev Immunol 2008; 8: 923-34.

96. Ozcan, U, Ozcan L, Yilmaz E, Düvel K, Sahin M, Manning $\mathrm{BD}$, et al. Loss of the tuberous sclerosis complex tumor suppressors triggers the unfolded protein response to regulate insulin signaling and apoptosis. Mol. Cell 2008; 29: 541-51.

97. Egger G, Dixon J. Inflammatory effects of nutritrional stimuli: further support for the need for a big picture approach to tackling obesity and chronic disease. Rev 2010; 11: 13749.

98. Matzinger, P. Tolerance, danger, and the extended family. Annu. Rev. Immunol. 1994; 12: 991-1045.

99. Takeuchi O, Akira S. Pattern recognition receptors and inflammation. Cell 2010; 140: 805-20.

100. Martinon F, Tschopp J. Inflammatory caspases and inflammasomes: master switches of inflammation. Cell Death Differ. 2007; 14: 10-22.

101. Martinon F, Burns K, Tschopp J. The inflammasome: a molecular platform triggering activation of inflammatory caspases and processing of prolL-beta. Mol. Cell 2002; 10: 417-26.

102. Zhou R, Tardivel A, Thorens B, Choi I, Tschopp J. Thioredoxininteracting protein links oxidative stress to inflammasome activation. Nat. Immunol. 2010; 11: 136-40.

103. Martinon F, Petrilli V, Mayor A, Tardivel A, Tschopp J. Goutassociated uric acid crystals activate the NALP3 inflammasome. Nature 2006; 440: 237-41.

104. Catania C, Binder E, Cota D. mTORC1 signaling in energy balance and metabolic disease. Int J Obes 2011; 35: 75161.

105. Rachdi L, Balcazar N, Osorio-Duque F, Elghazi L, Weiss A, Gould A, et al. Disruption of Tsc2 in pancreatic beta cells induces beta cell mass expansion and improved glucose tolerance in a TORC1-dependent manner. Proc Natl Acad Sci USA 2008; 105: 9250-55.

106. Fu A, Ng AC, Depatie C, Wijesekara N, He Y, Wang GS, et al. Loss of Lkb1 in adult beta cells increases beta cell mass and enhances glucose tolerance in mice. Cell Metab 2009; 10: $285-95$.

107. Hamada S, Hara K, Hamada T, Yasuda H, Moriyama $H$, Nakayama R, et al. Upregulation of the mammalian target of rapamycin complex 1 pathway by Ras homolog enriched in brain in pancreatic beta-cells leads to increased beta-cell mass and prevention of hyperglycemia. Diabetes 2009; 58 : 1321-32.

108. Schroder K, Zhou R, Tschopp J. The NLRP3 inflammasome: A sensor for metabolic danger? Science 2010; 327: 296-9.

109. Vandanmagsar B, Youm YH, Ravussin A, Galgani JE, Stadler $\mathrm{K}$, Mynatt RL, et al. The NLRP3 inflammasome instigates obesity-induced inflammation and insulin resistance. Nat Med. 2011;17:179-88.

110.Zhou R, Yazdi AS, Menu P, Tschopp J. A role for mitochondria in NLRP3 inflammasome activation. Nature. 2011; 469: 221- 
5.

111.Masters SL, Dunne A, Subramanian SL, Hull RL, Tannahill GM, Sharp FA,et al. Activation of the NLRP3 inflammasome by islet amyloid polypeptide provides a mechanism for enhanced IL-1beta in type 2 diabetes. Nat Immunol. 2010;11: 897-904.

112.Duewell P, Kono H, Rayner KJ, Sirois CM, Vladimer G, Bauernfeind FG, et al. NLRP3 inflammasomes are required for atherogenesis and activated by cholesterol crystals. Nature. 2010 ;464: 1357-61.

113.Wassel CL, Lange LA, Keating BJ, Taylor KC, Johnson AD, Palmer $\mathrm{C}$, et al. Association of genomic loci from a cardiovascular gene SNP array with fibrinogen levels in European Americans and African-Americans from six cohort studies: the Candidate Gene Association Resource (CARe). Blood. 2011; 117: 268-75.

114.Dehghan A, Dupuis J, Barbalic M, Bis JC, Eiriksdottir G, Lu C, et al. Meta-analysis of genome-wide association studies in 80 000 subjects identifies multiple Loci for C-reactive protein levels. Cirulation. 2011; 123: 731-8.

115.Denoble AE, Huffman KM, Stabler TV, Kelly SJ, Hershfield MS, McDaniel GE, et al. Uric acid is a danger signal of increasing risk for osteoarthritis through inflammasome activation. Proc Natl Acad Sci U S A. 2011; 108: 2088-93.

116.Vilaysane A, Chun J, Seamone ME, Wang W, Chin R, Hirota S, et al. The NLRP 3 inflammasome promotes renal inflammation and contributes to CKD. J Am Soc Nephrol. 2010; 21: 173244.

117.Satirapoj B. Review on pathophysiology and treatment of diabetic kidney disease. J Med Assoc Thai. 2010; 93 (suppl 6): S228-41.

118.Boden G. Free fatty acids, insulin resistance, and type 2 diabetes mellitus. Proc Assoc Am Phys. 1999; 111: 241-8.

119.Newgard CB, An J, Bain JR, Muehlbauer MJ, Stevens RD, Lien $\mathrm{LF}$, et al. A branched-chain amino acid- related metabolic signature that differentiates obese and lean humans and contributes to insulin resistance. Cell Metab. 2009; 9: 31126.

120. Lowell BB, Shulman GI. Mitochondrial dysfunction and type 2 diabetes. Science. 2005; 307: 384-7.

121. Houstis N, Rosen ED, Lander ES. Reactive oxygen species have a causal role in multiple forms of insulin resistance. Nature. 2006; 440: 944-8.

122. Ozcan U, Cao Q, Yilmaz E, Lee AH, Iwakoshi NN, Ozdelen E, et al. Endoplasmic reticulum stress links obesity, insulin action, and type 2 diabetes. Science. 2004; 306: 457-61.

123. Ouchi N, Kihara S, Funahashi T, Matsuzawa Y, Walsh, K. Obesity, adiponectin and vascular inflammatory disease. Curr. Opin. Lipidol. 2003; 14: 561-6.

124. Berg $\mathrm{AH}$, Scherer PE. Adipose tissue, inflammation, and cardiovascular disease. Circ. Res. 2005; 96: 939-49.

125. Samaras K, Botelh NK, Chisholm DJ, Lord RV. Subcutaneous and visceral adipose tissue gene expression of serum adipokines that predict type 2 diabetes. Obesity 2010; 18 : 884-9.

126. Fried SK, Bunkin DA, Greenberg AS. Omental and subcutaneous adipose tissues of obese subjects release interleukin-6: depot difference and regulation by glucocorticoid. J. Clin. Endocrinol. Metab. 1998; 83: 847-50.

127. Chatterjee TK, Stoll LL, Denning GM, Harrelson A, Blomkalns $\mathrm{AL}$, Idelman $\mathrm{G}$, et al. Proinflammatory phenotype of perivascular adipocytes: influence of high-fat feeding. Circ. Res. 2009; 104: 541-9.

128. Takaoka M, Nagata D, Kihara S, Shimomura I, Kimura Y, Tabata $\mathrm{Y}$, et al. Periadventitial adipose tissue plays a critical role in vascular remodeling. Circ. Res. 2009; 105: 906-11.

129. Ouchi N, Parker JL, Lugus JJ, Walsh K. Adipokines in inflammation and metabolic disease. Nat Rev Immunol
2011; 11: 85-97.

130. Ouchi N, Higuchi A, Ohashi K, Oshima Y, Gokce N, Shibata R, et al. Sfrp5 is an anti-inflammatory adipokine that modulates metabolic dysfunction in obesity. Science 2010; 329: 454-7.

131. Hummasti S, Hotamisligil GS. Endoplasmic reticulum stress and inflammation in obesity and diabetes. Circ Res 2010; 107: 579-91.

132. Hotamisligil GS. Endoplasmic reticulum stress and the inflammatory basis of metabolic disease. Cell. 2010; 140: 900-17.

133. Yang L, Li P, Fu S, Calay ES., Hotamisligil, GS. Defective hepatic autophagy in obesity causes insulin resistance. Cell Metab. 2010; 6: 467-78.

134. Levine B, Kroemer G. Autophagy in the pathogenesis of disease. Cell. 2008;132: 27-42.

135. Zitvogel L, Kepp O, Kroemer G. Decoding cell death signals in inflam- mation and immunity. Cell. 2010;140:798-804.

136. Lewis JR, Mohanty SR. Nonalcoholic fatty liver disease: a review and update. Dig Dis Sci 2010; 55: 560-78.

137. Lazo M, Clark JM. The epidemiology of nonalcoholic fatty liver disease: a global perspective. Semin Liver Dis 2008; 28 : 339-50.

138. Neuschwander-Tetri BA, Caldwell SH. Nonalcoholic steatohepatitis: summary of an AASLD Single Topic Conference. Hepatology 2003; 37: 1202-19.

139. Ferre P, Foufelle F. Hepatic steatosis: a role for the novo lipogenesis and the transcription factor SREBP-1C. Diabet Obes Metabolism 2010; 12 (Suppl 2): 83-92.

140. Mollica MP, Lionetti L, Putti R, Cavaliere G, Gaita M, Barletta A. From Chronic overfeeding to hepatic injury: Role of endoplasmic reticulum stress and inflammation. Nut Metabolism Cardiovasc Dis 2011; 21: 222-30.

141. Robertson, R. P., Harmon, J., Tran, P. O. \& Poitout, V. $\beta$-cell glucose toxicity, lipotoxicity, and chronic oxidative stress in type 2 diabetes. Diabetes 2004; 53: S119-24.

142. Weir GC, Bonner-Weir, S. Five stages of evolving $\beta$-cell dysfunction during progression to diabetes. Diabetes 2004; 53: S16-21.

143. Prentki, M. \& Nolan, C. J. Islet $\beta$ cell failure in type 2 diabetes. J. Clin. Invest. 2006; 116: 1802-12.

144. Hull RL, Westermark GT, Westermark P, Kahn SE. Islet amyloid: a critical entity in the pathogenesis of type 2 diabetes. J. Clin. Endocrinol. Metab. 2004; 89: 3629-.

145. Harding HP, Ron D. Endoplasmic reticulum stress and the development of diabetes: a review. Diabetes 2002; 51: S455-61.

146. Donath MY, Storling J, Maedler, K. \& Mandrup-Poulsen, T. Inflammatory mediators and islet $\beta$-cell failure: a link between type 1 and type 2 diabetes. J. Mol. Med. 2003; 81: 455-70.

147. Ehses JA, Ellingsgaard H, Boni-Schnetzler M, Donath MY. Pancreatic islet inflammation in type 2 diabetes: from $\alpha$ and $\beta$ cell compensation to dysfunction. Arch.Physiol. Biochem. 2009; 115: 240-7.

148. Donath MY, Schumann DM, Faulenbach M, Ellingsgaard $H$, Perren A, Ehses JA. Islet inflammation in type 2 diabetes: from metabolic stress to therapy. Diabetes Care 2008; 31 : S161-4.

149. Masters SL, Dunne A, Subramanian SL, Hull RL, Tannahill GM, Sharp FA, et al. Activation of the NLRP3 inflammasome by islet amyloid polypeptide provides a mechanism for enhanced IL-1 $\beta$ in type 2 diabetes. Nature Immunol. 2010; 11: 897-904.

150. Pickup JC, Mattock MB, Chusney GD, Burt D. NIDDM as a disease of the innate immune system: association of acutephase reactants and interleukin- 6 with metabolic syndrome X. Diabetologia 1997; 40: 1286-92. 
151. Spranger J, Kroke A, Möhlig M, Hoffmann K, Bergmann MM, Ristow $\mathrm{M}$, et al. Inflammatory cytokines and the risk to develop type 2 diabetes: results of the prospective population-based European prospective investigation into cancer and nutrition (EPIC)-potsdam study. Diabetes 2003; 52: 812-7.

152. Herder C, Illig T, Rathmann W, Martin S, Haastert B, MüllerScholze S, et al. Inflammation and type 2 diabetes: results from KORA Augsburg. Gesundheitswesen 2005; 67: S11521.

153. Herder C, Brunner EJ, Rathmann W, Strassburger K, Tabák AG, Schloot NC, et al. Elevated levels of the anti-inflammatory interleukin-1 receptor antagonist precede the onset of type 2 diabetes: the Whitehall II study. Diabetes Care 2009; 32: 421-3.

154. Pradhan AD, Manson JE, Rifai N, Buring JE, Ridker PM. C-reactive protein, interleukin 6 , and risk of developing type 2 diabetes mellitus. JAMA 2001; 286: 327-34.

155. Carstensen, M., Herder C, Kivimäki $M$, Jokela $M$, Roden $M$, Shipley $M J$, et al. Accelerated increase in serum interleukin-1 receptor antagonist starts 6 years before diagnosis of type 2 diabetes: Whitehall II prospective cohort study. Diabetes 2010; 59: 1222-7.

156. Marculescu R, Endler G, Schillinger M, lordanova N, Exner M, Hayden E, et al. Interleukin-1 receptor antagonist genotype is associated with coronary atherosclerosis in patients with type 2 diabetes. Diabetes 2002; 51: 3582-5.

157. Donath MY, Shoelson SE. Type 2 diabetes as an inflammatory disease. Nat Rev Immunol 2011; 11: 98-107.

158. Ehses JA, Meier DT, Wueest S, Rytka J, Boller S, Wielinga PY, et al. Toll-like receptor 2-deficient mice are protected from insulin resistance and $\beta$ cell dysfunction induced by a highfat diet. Diabetologia 2010; 53: 1795806.

159. Haversen L, Danielsson KN, Fogelstrand L, Wiklund O. Induction of proinflammatory cytokines by long-chain saturated fatty acids in human macrophages. Atherosclerosis 2009; 202: 38293.

160. Lee JY, Sohn KH, Rhee SH, Hwang D. Saturated fatty acids, but not unsaturated fatty acids, induce the expression of cyclooxygenase-2 mediated through Toll-like receptor 4 . J. Biol. Chem. 2001; 276: 16683-9.

161. Lee JY, Zhao L, Youn HS, Weatherill AR, Tapping R, Feng L, et al. Saturated fatty acid activates but polyunsaturated fatty acid inhibits Toll-like receptor 2 dimerized with Toll-like receptor 6 or 1. J. Biol. Chem. 2004; 279: 169719.

162. van de Veerdonk FL, Smeekens SP, Joosten LA, Kullberg BJ, Dinarello CA, van der Meer JW, et al. Reactive oxygen species-independent activation of the $\mathrm{IL}-1 \beta$ inflammasome in cells from patients with chronic granulomatous disease. Proc. Natl Acad. Sci. USA 2010; 107: 3030-3.

163. Meissner F, Seger RA, Moshous D, Fischer A, Reichenbach J, Zychlinsky A. Inflammasome activation in NADPH oxidase defective mononuclear phagocytes from patients with chronic granulomatous disease. Blood 2010; 116: 1570-3.

164. Dinarello CA. The role of the interleukin-1-receptor antagonist in blocking inflammation mediated by interleukin-1. N. Engl. J. Med. 2000; 343: 7324.

165. Dinarello CA. Biologic basis for interleukin-1 in disease. Blood 1996; 87: 2095-147.

166. Ehses JA, Lacraz G, Giroix MH, Schmidlin F, Coulaud J, Kassis $\mathrm{N}$, et al. IL-1 antagonism reduces hyperglycemia and tissue inflammation in the type 2 diabetic GK rat. Proc. Natl Acad. Sci. USA 2009; 106: 13998-4003.

167. Böni-Schnetzler M, Thorne J, Parnaud G, Marselli L, Ehses JA, Kerr-Conte, et al. Increased interleukin (IL)-1 $\beta$ messenger ribonucleic acid expression in $\beta$-cells of individuals with type 2 diabetes and regulation of IL-1 $1 \beta$ in human islets by glucose and autostimulation. J. Clin. Endocrinol. Metab. 2008; 93: 4065-74.

168. Böni-Schnetzler M, Boller S, Debray S, Bouzakri K, Meier DT, Prazak $R$, et al. Free fatty acids induce a proinflammatory response in islets via the abundantly expressed interleukin-1 receptor I. Endocrinology 2009; 150: 5218-29. 